\title{
Alocação de recursos adicionais de custeio em hospitais terciários do governo estadual do Ceará (Brasil) com base na avaliação de indicadores de eficiência
}

Recebido: 28 jan 2019 Aceito: 10 fev 2019

Autor de correspondência: helena.Is68@gmail.com

Conflito de interesses: Os autores declaram não haver nenhum interesse profissional ou pessoal que possa gerar conflito de interesses em relação a este manuscrito.
${ }^{(1)}$ Universidade Estadual do Ceará - UEC, Fortaleza, CE, Brasil.

\section{Resumo}

Um dos principais fatores que contribuem para ineficiência na distribuição de recursos em hospitais públicos é a inobservância de critérios que incentivem gestores a observar sistematicamente seus indicadores de eficiência e qualidade. Persistem formas tradicionais, baseado nos gastos do exercício anteriores, a exemplo de muitos países. Entretanto, já existem estudos que apontam formas do governo incentivar a eficiência na gestão hospitalar, por meio de recursos adicionais ao orçamento, baseado em indicadores de eficiência e qualidade hospitalar. Em 2013, M.H.L.S., a partir de sua experiência como gestora do orçamento da Secretaria de Saúde do Estado do Ceará - SES-CE, desenvolveu uma fórmula alocativa destinada a distribuir incentivos do tesouro estadual a partir de um índice chamado IDR-Hosp para cinco hospitais terciários por ela gerenciados. O resultado revelou que, além de cumprir a proposição distributiva eficiente, conseguiu identificar quais indicadores apresentaram resultados positivos ou não, como também as iniquidades na distribuição dos recursos de custeio no orçamento de 2011. O método foi implementado na elaboração do orçamento de 2012 e 2013 (parcialmente), sendo descartado em 2014 com a mudança de gestão, retornando ao método tradicional (incremental). A interrupção de critérios técnicos pode ocasionar interferência política e consequente desmotivação gerencial, considerando que anualmente o governo estadual incrementa recursos adicionais ao custeio desses hospitais. Questões do estudo: houve retrocesso na eficiência dos hospitais terciários do Estado após retirada da fórmula alocativa? Que indicadores contribuíram? O estudo objetiva avaliar a eficiência dos hospitais públicos terciários gerenciados pela SES-CE, por meio de um índice elaborado a partir de proxi de indicadores de eficiência e qualidade hospitalar, para fins de distribuição de recursos adicionais do tesouro estadual em seus orçamentos. O método consiste em pesquisa exploratória e avaliativa, quantitativa, utilizando dados secundários disponibilizados pela SES-CE e hospitais. Unidades de análise: cinco hospitais terciários gerenciados pela SESCE: "A"-HGF (geral); "B"-HM (especializado em doenças do coração e do pulmão); 
"C"-HGCC (geral, direcionado predominantemente para a saúde da mulher); "D"HIAS (especializado em crianças); e "E"-HSJ (especializado em doenças infecciosas), todos funcionando sob modelo de gestão administração direta. Para desenvolvimento do índice (IDR-Hosp) utilizou-se as taxas de mortalidade, permanência e reinternação hospitalar coletadas no Cadastro Nacional de Estabelecimentos de Saúde/Departamento de Informática do SUS CNES/DATASUS; taxa de infecção hospital (junto aos hospitais) e custos unitários finais dos hospitais (Sistema SICS/Web/SES-CE), a exemplo de Sousa (2013), para permitir análise comparativa. O índice é desenvolvido por meio da variação das taxas do período 1 (2008 a 2010) com o período 2 (2011 a 2013) dos indicadores selecionadas, medindo as mudanças marginais dos indicadores que são produzidas pelo funcionamento dos hospitais. Considerando que os hospitais são incomparáveis por terem objetivos diferentes, optou-se por compará-los com eles próprios. O resultado é fruto do incremento das variáveis consideradas, todos com mesma direção (quanto menor melhor). A partir dos resultados de cada indicador, calcula-se a média geral do hospital, de forma que aqueles que obtiveram variação abaixo de "1" foram considerados eficientes e aqueles com variação acima de "1" ineficientes. A distribuição de recursos é dada pelo inverso das médias. Elaborou-se dois índice: índice " $X$ " leva em consideração a variação das médias e o índice " $Y$ " considera a variação das médias menos o desvio padrão. A sugestão é aplicar nos dois primeiros anos o índice " $Y$ " e depois o índice " $X$ " indefinidamente. Para definição do IDR/Hop utilizou-se o aplicativo estatístico SPSS, versão 22. Valores monetários foram atualizados pelo IGP-M, com base em 2013. Têm-se como resultados: pela fórmula " $A$ " observa-se que dos cinco hospitais estudados, três foram considerados eficientes, por conseguir reduzir a variação global de seus indicadores: " $E$ " $(-13,3 \%), A,(-5,9 \%)$ e por último o "C" com (-1,71\%). Os demais aumentaram na seguinte proporção: " $D$ " (15,13\%) e "B" (3,48\%), sendo considerados como ineficientes, consequentemente não receberiam recursos adicionais para o custeio no ano seguinte. Melhor performance atribuiu-se ao " $E$ " que receberia 35,7\%, seguido do " $A$ " com 32,9\% e, por último o " $\mathrm{C}$ ", com 32,5\%. O que contribuiu para rebaixar o " $\mathrm{D}$ " foram: aumentos de $47,7 \%$ do custo do atendimento nos ambulatórios; $28,9 \%$ do custo da cirurgia; $35,5 \%$ no custo do atendimento na emergência; $92,5 \%$ no custo do exame no serviço de imagem; $18,6 \%$ no custo paciente/dia do serviço de UTI. Em relação ao $B$, o que pesou foram os aumentos de: 3,9\% no custo da cirurgia, $12,8 \%$ no custo dos exames laboratoriais, $5,3 \%$ no custo exame de imagem, $19,3 \%$ no custo do paciente-dia dos setores de internação, $51,2 \%$ no custo do atendimento no PAD, 4\% na taxa de infecção hospitalar, e 6,4\% na taxa de reinternação. Estudo de Sousa (2013) utilizando a mesma metodologia com os mesmos hospitais revelou resultados diferentes. Apenas o " $E$ " manteve nível de eficiência em ambos os estudos, com pequena diferença, em Sousa (2013) receberia 52,3\% teria de dividir apenas com dois hospitais. Neste estudo, dividindo entre três, ele receberia $35,7 \%$. $O$ " $B$ " que ficou em segundo lugar no estudo de Sousa (2013), perdeu espaço para o " $A$ " e " $C$ ", deixando de receber 
recursos adicionais porque reduziu sua eficiência. $O$ " $C$ " que ficou de fora do estudo referido, passou a compor o conjunto de hospitais que melhoraram sua eficiência e, portanto teriam direito a receber incentivo adicional. A situação do " $\mathrm{D}$ " continua no mesmo patamar de ineficiência, apresentando dificuldades gerenciais para controlar seus indicadores de eficiência hospitalar. Pela fórmula "B" (média menos desvio padrão), apenas o " $D$ " ficaria fora da partilha dos recursos adicionais para o custeio, sendo o único cujo índice atingiu 1,04, portanto, aumento de $4 \%$. Os demais ficaram bem próximos, apresentando melhor nível de eficiência. Estudo de Sousa (2013) revelou que esse hospital mostrou resultado positivo, o que vem a ser motivo de atenção, por ter apresentado retrocesso em sua eficiência. Conclusão: considerando o resultado da fórmula " $X$ " e " $Y$ ", verifica-se que houve avanços e retrocessos entre o estudo de Sousa (2013) e os resultados aqui obtidos. Isso possivelmente é decorrência do não monitoramento de indicadores importantes para o melhor desempenho dos hospitais, motivado pelo retrocesso na forma de distribuir recursos. Acreditase que o retorno de critérios que incentivem o monitoramento dos indicadores levem gestores a alcançar graus crescentes de eficiência e qualidade.

Descritores: Alocação de Recursos; Eficiência; Economia da Saúde. 